\title{
El Derecho Humano de la libertad de tránsito Vs los retenes administrativos.
}

\author{
Cruz Banda Cuellar \\ Miguel Eduardo Martínez Delgado \\ César Miguel Rodriguez Campoy
}

\section{Resumen}

Un tema de suma importancia para todos los mexicanos desde hace un tiempo a la fecha es el acto de molestia representado en nuestra realidad jurídica por los llamados retenes administrativos o bien los alcoholímetros, que en principio muchos constitucionalistas aducen que es una violación al derecho humano de la libertad de tránsito y por lo tanto éstos representan un acto de molestia para quienes se les detiene en dichos puestos de revisión. Analizar ¿cómo debe ser interpretada la libertad de tránsito? y ¿cuáles son sus limitantes?, debe ser relevante para determinar si hay o no violación de derechos humanos o es justificable un control preventivo. No debemos pasar por alto que vivimos en una sociedad que cada vez exige más sus derechos encaminada a una visión constitucional por encima del legalismo.

Palabras clave: Derechos humanos . retenes administrativos, libertad de tránsito. 


\section{INTRODUCCION}

En esta investigación se presenta un análisis relativo a la problemática que se está viviendo en el estado de Sonora ya que es un problema constante para la mayor parte de los ciudadanos debido a la forma inadecuada y del mal proceso de las autoridades al establecer sus retenes en distintas zonas no cumpliendo con lo establecido por la ley y generando así bastante inconformidad.

Es por esta razón que se abordaran los siguientes puntos a tratar, principalmente los fundamentos jurídicos en que están basados los retenes administrativos ya que en la Constitución Política de los Estados Unidos Mexicanos establece en su artículo 11ำ, que todo individuo tiene derecho al libre tránsito a excepción de las leyes que de ellas emanan como lo son La ley de Tránsito para el Estado de Sonora donde se fundamenta el porqué de los retenes administrativos.

En la ley anteriormente mencionada, su principal objetivo es llevar a cabo la protección de este derecho humano ya que al no cumplir con lo que se establece y al no tomar un control necesario se pone en peligro la integridad de las personas.

\section{Planteamiento del problema.}

En el Estado de Sonora, ¿Están legalmente constituidos los retenes administrativos? ¿Actúan con apego a las normas jurídicas estos retenes? ¿Realmente se hace un uso pleno del derecho humano de la libertad de tránsito? Esas son algunas de las interrogantes que nos planteamos antes de realizar el presente trabajo, y en base a una investigación documental que realizamos pretendemos darle una respuesta a cada una de ellas, ya que consideramos que es un problema real y vigente que se da día a día en nuestro estado y a pesar 


\section{Revista de Investigación \\ Académica sin Frontera ISSN: $2007-8870$ \\ http://revistainvestigacionacademicasinfrontera.com}

de ser algo muy común en la practica la mayor parte de la población tiene estas dudas.

Primeramente consideramos que era de manera esencial hacer una breve cita de los que dice nuestra legislación, sobre lo que es el derecho humano de la libertad de tránsito, así como los cambios que ha venido presentando con el paso del tiempo ya que al igual que la mayoría de las leyes en nuestro país tienen que ir evolucionando y adecuándose a las necesidades de los ciudadanos. Nuestra Carta Magna nos lo estipula de una manera tal vez, no muy clara, desde nuestro punto de vista, como a continuación se muestra en su artículo 11 constitucional:

"Artículo 11. Toda persona tiene derecho para entrar en la República, salir de ella, viajar por su territorio y mudar de residencia, sin necesidad de carta de seguridad, pasaporte, salvoconducto u otros requisitos semejantes. El ejercicio de este derecho estará subordinado a las facultades de la autoridad judicial, en los casos de responsabilidad criminal o civil, y a las de la autoridad administrativa, por lo que toca a las limitaciones que impongan las leyes sobre emigración, inmigración y salubridad general de la República, o sobre extranjeros perniciosos residentes en el país. En caso de persecución, por motivos de orden político, toda persona tiene derecho de solicitar asilo; por causas de carácter humanitario se recibirá refugio. La ley regulará sus procedencias y excepciones."

Este derecho es algo que se viene contemplando desde la constitución central de 1836 de nuestro país, la cual hacía mención de la libertad de tránsito en su artículo $2^{2}$ fracción $\mathrm{VI}$, el cual mencionaba lo siguiente:

"No podérsele impedir la traslación de su persona y bienes a otro país, cuando le convenga, con tal de que no deje descubierta en la República responsabilidad 


\section{Revista de Investigación \\ Académica sin Frontera ISSN: 2007-8870 \\ http://revistainvestigacionacademicasinfrontera.com}

de ningún género y satisfaga, por la extracción de los segundos, la cuota que establezcan las leyes"

Si bien ha sufrido grandes cambios, desde su creación a la fecha, la esencia se ha conservado con el paso de los años ya que es un derecho humano fundamental y necesario ya que todos los individuos tenemos esta necesidad de trasladarnos en lo largo de nuestras vidas, ya sea de una manera básica y esencial o por recreación.

Este artículo 11 de nuestra Constitución Política Mexica vigente hace referencia a cuatro tipos de libertades diferentes que tenemos todos los mexicanos, como lo son: la libertad de entrar en el territorio que ocupa nuestra República Mexicana, salir de ella misma, viajar por todo lo que comprende su territorio y así mismo mudar de residencia si así se desea.

En esta ocasión nos centraremos específicamente en el estudio de una de ellas que es la libertad de viajar dentro del estado mexicano y nos estaremos apoyando en otro artículo constitucional muy importante ya que este guarda una estrecha relación con el tema que estamos desarrollando, puesto que los retenes generan hasta cierto punto un acto de molestia para la población; el artículo 16 de nuestra carta magna; el cual establece en su párrafo primero que: "nadie puede ser molestado en su persona, familia, domicilio, papeles o posesiones, sino en virtud de mandamiento escrito de la autoridad competente, que funde y motive la causa legal del procedimiento".

En la actualidad nosotros consideramos que existen algunas conductas llevadas a cabo por el estado que resultan contrarias a los preceptos que se estipulan en nuestra legislación mexicana, tal y como es en el caso de los retenes administrativos y los exámenes de alcoholemia, mismos que se realizan en algunos puntos estratégicos de las ciudades. 


\section{Revista de Investigación \\ Académica sin Frontera ISSN: 2007-8870 \\ http://revistainvestigacionacademicasinfrontera.com}

Dichos puntos se han vuelto cada día más frecuentes en la práctica, cada día se pueden observar más de ellos lo cual consideramos que resulta ser un acto de molestia para la población en general, ya que existen quejas y/o denuncias ante organismos internacionales como la Comisión Nacional De Derechos Humanos acerca de estos puestos de control ya que en varios de ellos, las personas encargadas de realizar este tipo de operativos no actúan conforme a lo que la ley establece.

A continuación pasamos a dar respuesta a cada una de las preguntas planteadas al principio de este trabajo, para después pasar a una breve conclusión de los resultados obtenidos de esta investigación documental.

\section{Normas jurídicas que fundamentan los retenes administrativos}

El estado hace mención a varios artículos constitucionales para fundamentar el establecimiento de los retenes, entre ellos podemos señalar los siguientes:

a) Artículo 16 constitucional, el cual hace mención a la detención en flagrancia.

b) Artículo 21 constitucional, refiriéndose a la seguridad pública del Estado, ya que este tipo de operativos lleva ese enfoque al evitar la comisión o consumación de delitos.

c) Articulo 89 donde se faculta al presidente para hacer uso de las fuerzas armadas para buscar que prevalezca la paz.

d) Reglamentos locales como lo es nuestra Ley De Tránsito Del Estado De Sonora en su artículo 213 BIS.

Marco jurídico del establecimiento de los retenes en México. 


\section{Revista de Investigación \\ Académica sin Frontera ISSN: 2007-8870 \\ http://revistainvestigacionacademicasinfrontera.com}

De acuerdo al artículo 213 Bis de la Ley de Tránsito del Estado de Sonora, establece la modalidad con la que deberían de establecerse y operar estos puntos de revisión.

.Estipula que en todos Los Municipios del Estado en el que se implementen este tipo de operativos de alcoholimetría para determinar el grado de alcoholemia de conductores de vehículos deberán cumplir, como mínimo, con los siguientes requisitos:

a) Estos deberán Establecerse en lugares de máxima visibilidad y seguridad, misma que sea adecuada para los conductores y para el personal que lleve a cabo los operativos;

b) Contar con iluminación necesaria para mantener la seguridad para los conductores y para el personal que se encuentre realizando los operativos;

c) Contar con un área establecida de acercamiento inicial o primer contacto; misma que servirá para presentarse oficialmente y dar la justificación del porque se está realizando el operativo.

d) Contar con un área de prueba de alcoholimetría;

e) Contar con la presencia por lo menos de un médico legista y un juez calificador autorizado por el ayuntamiento, así como personal de Organizaciones de la Sociedad Civil y de personal autorizado por la Comisión Estatal de los Derechos Humanos; 


\section{http://revistainvestigacionacademicasinf rontera.com}

f) Se deberá imprimir el resultado de la prueba de alcoholemia; y

g) Contar con todos los recursos materiales establecidos en el Programa Nacional del Alcoholimetría.

\section{El uso pleno del derecho humano de la libertad de tránsito.}

Como antes mencionamos la libertad de tránsito es una necesidad que todos los individuos tenemos y por ende se engloba dentro de los derechos humanos fundamentales que todo ser humano debe de tener por el simple hecho de ser persona, mismos que deben de ser respetados ya sea por individuos 0 autoridades.

En cuanto a lo que se refiere la libertad de tránsito no se hace un uso pleno de ella, si bien es verdad que no se encuentra limitado este derecho en su totalidad si representa un tipo de molestia e impedimento para desplazarte libremente por determinados lugares establecidos dentro del territorio de nuestra República Mexicana; además de ocasionar actos de molestia en la propiedad privada de cada individuo.

\section{Referencias teóricas}

La libertad de tránsito es un derecho constitucional violentado por las autoridades cosa que se le ha insistido mucho al gobierno para que no los lleven a cabo lo cual hacen caso omiso, argumentando que son medios que utilizan para darle mejor seguridad a la ciudadanía. Dentro de las garantías el gobernado se nos especifica que ninguna autoridad debe de revisar lo que es propiedad privada cosa que se lleva acabo cuando se nos prohíbe nuestra libertad de tránsito en algún puesto de revisión, esto es un problema jurídico con el cual se debe lidiar dentro de nuestro territorio en las carreteras o en la misma ciudad podemos 


\section{Revista de Investigación \\ Académica sin Frontera ISSN: $2007-8870$ \\ http://revistainvestigacionacademicasinfrontera.com}

encontrar los ya conocidos retenes, estos si bien es cierto no prohíben que una persona circule pero si violentan derechos humanos y más bien derechos constitucionales al detenernos cuestionarnos y revisar nuestra propiedad e identidad en el momento de ser revisados por una autoridad. Por lo que vienen siendo actos anticonstitucionales ya que no existe un mandamiento de autoridad compete te donde ellos funden y motiven la causa legal de la revisión. Una manera de combatir esta arbitrariedad seria denunciar la responsabilidad administrativa, de quienes han ordenado tales puestos de vigilancia, inspección o revisión, por violar un principio de legalidad.

La carta magna nos autoriza a todos los gobernados a viajar por todo el territorio nacional sin necesidad de un salvoconducto o pasaporte entonces la manera de actuar de la autoridad con la finalidad de brindarnos seguridad pero de una manera que violenta nuestros derechos. Muy claramente el articulo 11 nos habla de nuestra libertad de tránsito dentro de nuestro territorio sin ser molestado, así pues la constitución Política de los Estados Unidos mexicanos protege este bien jurídico, a merced de que todas las personas tenemos la potestad de trasladarnos a donde más nos plazca siempre y cuando no afectemos la propiedad de otros o no nos encontremos dentro de los supuestos de restricción a ésta libertad, que prescribe la Constitución.

Existen casos dónde el derecho de tránsito no es absoluto, sino que está restringido previendo la Constitución diversos supuestos delimitantes a ésta garantía, los que tienden a regular aspectos relacionados con la legal estancia de las personas en el país y la posibilidad de hacer frente a calamidades públicas, así mismo, ésta libertad se restringe por cuestiones de responsabilidad penal y civil.

\section{Metodología}




\section{Revista de Investigación \\ Académica sin Frontera ISSN: 2007-8870 \\ http://revistainvestigacionacademicasinfrontera.com}

La presente ponencia fue realizada en base a una investigación bibliográfica que realizamos en la biblioteca de la Universidad De Sonora Unidad Regional Sur y algunas páginas de internet, en la cual a partir de analizar los diferentes puntos de vista de varios autores adoptamos el cual compartía nuestra misma ideología, de igual manera se tomó en cuenta lo que contemplan nuestras normas jurídicas, tesis y algunos tratados internacionales de los cuales nuestro país forma parte.

A partir de este análisis pudimos llegar a una conclusión definitiva acerca de la problemática planteada, misma que más adelante se estará presentando.

\section{Conclusión}

Después de haber realizado la presente investigación pudimos concluir que nuestro derecho humano fundamental de la libertad de tránsito no se está cumpliendo en su totalidad en nuestro Estado, ya que la implementación de este tipo de operativos como lo son los retenes representan una obstrucción a la libre circulación.

Si bien es verdad, como lo expone y fundamenta el estado que este tipo de operativos se llevan a cabo para combatir a la delincuencia y en ocasiones detienen a presuntas personas cometiendo actos ilícitos, por otro lado también se encuentran las personas que actúan conforme lo establece la ley y reciben un trato no muy adecuado, empezando por no respetar el principio jurídico de presunción de inocencia.

En cuanto a los puntos de alcoholimetría si se encuentran regulados por la Ley De Tránsito Del Estado De Sonora, pero solo en la ley, ya que en la práctica se puede observar algo muy diferente a lo establecido por las normas. En nuestra vida diaria es común observar como este tipo de puestos de control no cumplen con lo que establece el artículo 213 BIS de la ley en mención violentando de una manera clara lo estipulado por el articulo 16 y 20 constitucionales. 
Año 9. Núm. 24 (Edición especial julio- diciembre 2016)

Revista de Investigación

Académica sin Frontera ISSN: $2007-8870$

http://revistainvestigacionacademicasinfrontera.com

Fuentes de consulta.

\section{Bibliográficas.}

- Ignacio Burgoa. (2008). Las garantías individuales. México: Ediciones Porrúa.

- Alberto del Castillo del Valle. (2005). Garantías del gobernado. México: Ediciones jurídicas alma.

\section{Leyes}

- Ley De Transito Para el Estado De Sonora.

- Constitución Política De Los Estados Unidos Mexicanos.

- Declaración Universal De Los Derechos Humanos.

\section{Fuentes de internet.}

- $\quad$ https://app.vlex.com/\#vid/78730184 